\title{
Propeptide levels of type III and type I procollagen in the serum and bronchoalveolar lavage fluid of patients with pulmonary sarcoidosis
}

\author{
L. Lammi*, V. Kinnula**, S. Lähde+, J. Risteli++\#, P. Pääkkö§, E. Lakari**, L. Ryhänen**\#
}

Propeptide levels of type III and type I procollagen in the serum and bronchoalveolar lavage fluid of patients with pulmonary sarcoidosis. L. Lammi, V. Kinnula, S. Lähde, J. Risteli, P. Pääkkö, E. Lakari, L. Ryhänen. @ERS Journals Ltd 1997.

ABSTRACT: No single test is available to reliably assess the activity or prognosis of pulmonary sarcoidosis. In this study, we have evaluated two procollagen markers, aminoterminal propeptide of type III procollagen (PIIINP) and carboxyterminal propeptide of type I procollagen (PICP) in serum and bronchoalveolar lavage fluid (BALF) and compared them to other disease markers of pulmonary sarcoidosis, such as serum level of angiotensin converting enzyme (S-ACE) or serum interleukin-2 receptor (S-IL-2R).

Bronchoalveolar lavage was performed in $\mathbf{4 0}$ sarcoidosis patients without (stages 0-I) and 20 patients with lung parenchymal involvement (stages II-III), as well as in 17 controls. Serum (S)- and BALF-PIIINP and PICP, S-ACE, S-IL-2R, BALF-albumin, BALF- lymphocytes and mast cells were determined in these patients.

BALF-PIIINP was clearly and S-PIIINP slightly elevated in sarcoidosis compared to the controls. Similarly BALF-PICP, but not S-PICP, was significantly higher in sarcoidosis. BALF-PIIINP, but not BALF-PICP correlated with S-ACE and S-IL-2R levels. Patients with lung parenchymal disease had higher S-ACE and BALF-PIIINP, but neither S-IL-2R, S-PIIINP nor S- or BALF-PICP were elevated. S-PIIINP and SIL-2R but not S-ACE were higher in symptomatic than nonsymptomatic patients. Symptomatic patients with parenchymal disease had elevated BALF-PIIINP whereas in the symptomatic nonparenchymal group S-PIIINP was elevated.

In conclusion, this is the first study to evaluate carboxyterminal propeptide of type I procollagen in sarcoidosis and showed elevated levels in bronchoalveolar lavage fluid. In contrast to the levels of bronchoalveolar lavage fluid aminoterminal propeptide of type III procollagen, levels of carboxyterminal propeptide of type I procollagen did not correlate with serum level of angiotensin converting enzyme and serum interleukin-2 receptor levels, suggesting that carboxyterminal propeptide of type I procollagen may be less suitable disease marker in sarcoidosis than aminoterminal propeptide of type III procollagen. However, the role of carboxyterminal propeptide of type I procollagen as an indicator of fibrogenesis must be further studied.

Eur Respir J 1997; 10: 2725-2730.
*Dept of Pulmonary Medicine, Vaasa Central Hospital, Vaasa, Finland, **Dept of Internal Medicine, +Diagnostic Radiology, ${ }^{++}$Clinical Chemistry, ${ }^{\#}$ Medical Biochemistry, and \$Pathology, University of Oulu, Oulu, Finland.

Correspondence: L. Ryhänen

Dept of Internal Medicine

University of Oulu

Kajaanintie 50

Fin 90220 Oulu

Finland

Keywords: Aminoterminal propeptide of type III procollagen

bronchoalveolar lavage fluid

carboxyterminal propeptide of type I procollagen

epithelial lining fluid

pulmonary sarcoidosis

serum

Received: December 161996

Accepted after revision September 71997

A preliminary report of this work has been presented at European Respiratory Society annual congress, Stockholm, September $7-11,1996$. This work was partly supported by grants from Finnish Anti-Tuberculosis Association Foundation, Finland, and from Technology Development Centre, Finland (TEKES) and Oy Suomen ASTRA.
Activity and outcome of sarcoidosis is difficult to assess. In most cases the prognosis is good and patients recover completely. However, 10-20\% of them are at risk of developing progressive pulmonary fibrosis $[1,2]$.

Serum level of angiotensin converting enzyme (S-ACE) is a commonly used indicator of the activity of sarcoidosis $[3,4]$, and serum interleukin-2 receptor (S-IL-2R) has also been reported to be elevated in active sarcoidosis $[5,6]$. Other markers of the activity include ${ }^{67} \mathrm{Ga}$ scan, computed tomography and bronchoalveolar lavage fluid (BALF)-cell populations such as CD4/CD8 ratio, but all these parameters are more or less nonspecific. Certain markers of collagen metabolism, such as aminoterminal propeptide of procollagen type III (PIIINP) from serum and BALF, have been employed to evaluate the disease activity. However, the results have been inconclusive both when PIIINP has been measured from serum [7-10] BALF [10-15]. To our knowledge, there is only one study in which serum carboxyterminal propeptide of type I procollagen (S-PICP) was investigated in sarcoidosis [16] showing elevated SPICP levels in newly diagnosed sarcoidosis. Thus, activity of sarcoidosis is still difficult to assess. For instance, a World Association for Sarcoidosis and Other Granulomatous Disorders (WASOG) meeting report (1994) [4] concluded that the only routine tests to stage the activity of sarcoidosis are clinical investigation, chest radiography and lung function testing.

Pulmonary fibrosis is a severe and irreversible complication of sarcoidosis, often causing a permanent invalidization of the patient. Several attempts have been made to develop prognostic markers to evaluate development of pulmonary fibrosis. S-ACE does not reflect the fibrogenesis [17]. In some studies, high amount of lymphocytes, especially certain subsets of T-lymphocytes in BALF have 
been considered to predict active disease progression in sarcoidosis [18], while in some others this association has not been observed [19].

Pulmonary fibrosis starts with type III collagen accumulation which is largely replaced by type I collagen and formation of tight collagen fibres [20]. PIIINP reflects synthesis of type III procollagen, although it can to some extent indicate degradation of type III collagen fibres [21]. Carboxyterminal propeptide of type I procollagen (PICP), on the other hand, reflects synthesis of type I procollagen, but not degradation of type I collagen fibres [21]. Thus, measurement of procollagen markers, as well as other markers of procollagen metabolism (e.g. prolyl hydroxylase and galactosyl hydroxylysyl glucosyltransferase) would theoretically offer a superior way of evaluating collagen metabolism and development of fibrosis. However, the results using these methods have also been conflicting [7, 22, 23].

In this study we have modified serum aminoterminal propeptide of procollagen type III (S-PIIINP) and S-PICP radioimmunoassay for the measurement of these procollagen peptides in BALF samples. BALF-PICP has not been evaluated in sarcoidosis before. Since the activity of sarcoidosis is difficult to assess, we examined how the levels of these collagen markers either in serum or BALF would correlate with other markers such as chest radiography, S-ACE or S-IL-2R.

\section{Materials and methods}

\section{Study population}

The study included 60 consecutive sarcoidosis patients who were admitted to the pulmonary department of Päivärinne Hospital (Muhos, Finland) between February 1990 and May 1992. All patients with nonparenchymal disease were newly diagnosed. Five patients in the parenchymal group had previously diagnosed disease; two of them were on oral corticosteroid therapy. Forty five patients had symptoms typical for sarcoidosis and 15 were symptomless at presentation. Characteristics of the study population are presented in table 1.

Chest radiograph examinations were performed and first interpreted by a physician specialized in respiratory medicine, and then interpreted retrospectively and blindly by an experienced thoracic radiologist. Nodular hilar enlargement was the criterion for hilar adenopathy, and reticular, nodular and/or linear pattern for interstitial disease [24]. Stages 0-I sarcoidosis were scored as nonparenchymal and stages II-III as parenchymal disease.

Histological diagnosis was confirmed in 35 patients by biopsies taken either transbronchially, via mediastinoscopy, from superficial lymph node, or from the skin. Sixteen out of 20 patients in the group with lung parenchymal changes and 19 out of 40 patients with nonparenchymal disease had histological changes typical for sarcoidosis. In the remaining 25 patients, diagnosis was based on typical clinical picture, marked lymphocytosis in the BALF and typical chest radiographic finding as well as exclusion of other diseases. S-PIIINP is known to be elevated in liver diseases. In our patients, serum alanine aminotransferase was elevated in three patients, but their S-PIIINP was within normal range.
Table 1. - Characteristics of the study population

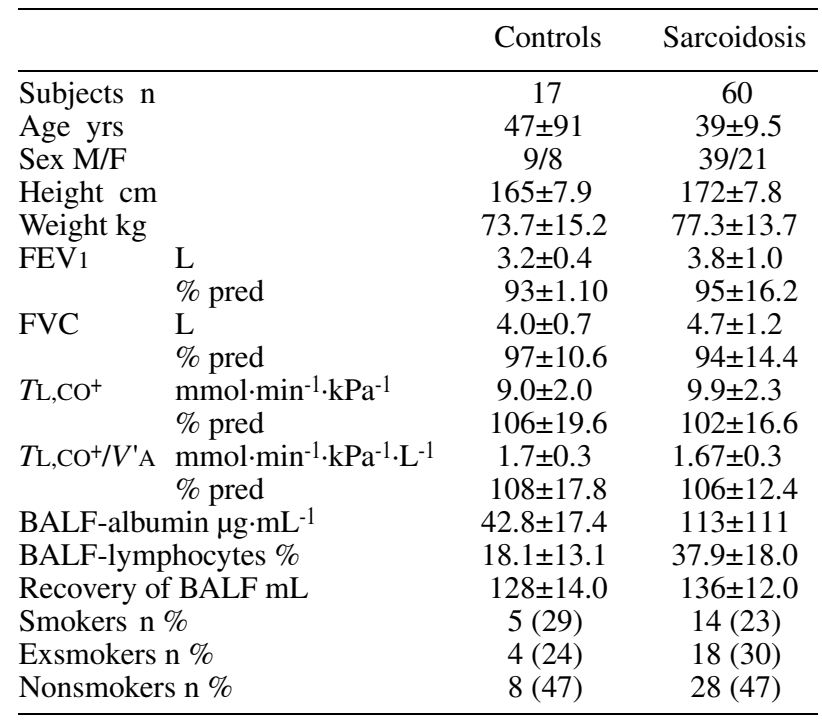

Values are mean \pm SD. ${ }^{+}$: available from 16 controls and 57 sarcoidosis patients. M: male; F: female; $\mathrm{FEV}_{1}$ : forced expiratory volume in one second; FVC: forced vital capacity; TL,CO: transfer factor of the lung for carbon monoxide; $V$ 'A: alveolar ventilation; BALF: bronchoalveolar lavage fluid; \% pred: percentage of predicted value.

The control group comprised 17 subjects who underwent fibreoptic bronchoscopy because of prolonged cough, haemoptysis or other minor respiratory symptoms (table $1)$. Four of the controls were later considered asthmatic. Chest radiographs were normal in all controls.

Informed consent was obtained from each subject beforehand, and the research protocol was approved by the Ethics Committee of Päivärinne Hospital.

\section{Methods}

Serum ACE was measured with a method described by HarJanNe [25] in 1984 modified for Kone Spesific ${ }^{\circledR}$-analyser (Kone Oy, Espoo, Finland). Interleukin-2 receptor (IL-2R) was analysed with enzyme-linked immunosorbent assay (ELISA) (DAKO A/S, DK 2600 Glostrup, Den-mark). Albumin and urea were measured by standard laboratory methods. Serum PIIINP and S-PICP were determined by commercial radioimmunoassay kits (OrionDiagnostica Oy, Oulunsalo, Finland) [26, 27], employing human antigen and specific polyclonal antibodies.

Fibreoptic bronchoscopy for sampling BALF was performed under local anaesthesia with lignocain. Patients were premedicated with atropine and diazepam. The bronchoscope was wedged into the right middle lobe bronchus or into the left lingula. Saline solution was installed in 10 aliquots of $20 \mathrm{~mL}$. After each installation the fluid was gently aspirated and collected in a plastic bottle kept on ice. The mean $\pm S D$ recovery of the lavage fluid was $136 \pm 12$ $\mathrm{mL}$ in patients and $128 \pm 14 \mathrm{~mL}$ in controls. After centrifugation $(400 \times \mathrm{g}$ for $15 \mathrm{~min}), 30 \mathrm{~mL}$ cell free supernatant was stored at $-20{ }^{\circ} \mathrm{C}$ for later assays of PIIINP and PICP.

Total number of the cells was counted in Bürger haemocytometer, and cell viability was assessed by trypan blue exclusion. One millilitre of lavage fluid was fixed in 
equal volume of $95 \%$ ethanol and Millipore filter preparations were made with Papanicolaou staining. Cytocentrifuge preparations (700 revolutions per minute (rpm), 5 mini Cytospin 2, Shandon Instruments, Astmoor, UK) of unfixed cells (roughly 100,000 cells $\cdot$ slide $^{-1}$ ) were air-dried overnight at room temperature and stained with MayGrünwald-Giemsa. For differential counts, 200 cells were counted on both filter and cytocentrifuge preparations.

For assaying BALF-PIIINP and PICP by radioimmunoassay, the original methods were modified, so that no concentration or further processing of the sample was necessary. Human antigens were employed to induce polyclonal anti-PIIINP and PICP antibodies [26, 27]. In the final form of the BALF-PIIINP assay, $1 \mathrm{~mL}$ of BALF or appropriate standards, adjusted to $0.1 \mathrm{M}$ phosphate buffer, was incubated with $200 \mu \mathrm{L}$ of 125 I-PIIINP tracer solution diluted 1:1000 with phosphate-buffered saline containing $0.04 \%$ Tween -20 (PBS/Tween) and $100 \mu \mathrm{L}$ antiserum (diluted 1:1000 with $\mathrm{PBS} /$ Tween) at $37^{\circ} \mathrm{C}$. After $2 \mathrm{~h}$ incubation, $1.5 \mathrm{~mL}$ of secondary antibody (the original solid phase reagent concentrated $\times 2$ ) was added and the tubes were further incubated at room temperature for $30 \mathrm{~min}$, centrifuged at $3400 \times \mathrm{g}$ at $4^{\circ} \mathrm{C}$ for $15 \mathrm{~min}$, and the radioactivity in the precipitates counted. The standard curves were calculated using an automatic gamma-counter (Clinigamma 1272; Wallac, Turku, Finland). The BALF-PICP assay was performed similarly; $200 \mu \mathrm{L}$ 125I-PICP tracer solution (dilution 1:2,500) and $150 \mu \mathrm{L}$ antiserum (dilution 1:1,000) were incubated with the samples and then the immunocomplex was precipitated with $1 \mathrm{~mL}$ of secondary antibody (the original solid concentrated $\times 2$ ). The results are expressed either as micrograms propeptide per litre of recovered BALF or as micrograms of propeptide per litre of epithelial lining fluid (ELF) estimated by urea method [28]. The sensitivities of the original methods are $0.2 \mu \mathrm{g} \cdot \mathrm{L}^{-1}$ with $200 \mu \mathrm{L}$ serum sample for PIIINP and $1.2 \mu \mathrm{g} \cdot \mathrm{L}^{-1}$ with $100 \mu \mathrm{L}$ serum sample for PICP. The intra- and interassay variations for PIIINP are 4.3 and $5.3 \%$ and for PICP 3.2 and $6.6 \%$, respectively.

Pulmonary function tests including forced expiratory volume in one second (FEV1) and forced vital capacity (FVC) were measured with flow volume spirometer and transfer factor of the lung for carbon monoxide $(T \mathrm{~L}, \mathrm{CO})$ and specific diffusion coefficient ( $T \mathrm{~L}, \mathrm{CO} /$ alveolar ventilation $\left.\left(V^{\prime} \mathrm{A}\right)\right)$ with single breath technique.

\section{Statistical analysis}

In statistical evaluation, nonparametric tests were used. Correlations were assessed with Spearman correlation coefficient test and differences between groups were assessed by Mann-Whitney U-test. A p-value of less than 0.05 was taken as statistically significant.

\section{Results}

Serum-PIIINP and BALF-PIIINP were significantly elevated in the patients with sarcoidosis. BALF-PIIINP was detectable in two out of 17 control subjects, and in 22 out of 60 sarcoidosis patients. S-PICP levels did not differ significantly in the controls and sarcoidosis patients, whereas BALF-PICP was significantly higher in sarcoidosis.
Table 2. - Serum and BALF-PIIINP and -PICP concentrations in the controls and sarcoidosis patients

\begin{tabular}{lcc}
\hline & Controls & Sarcoidosis \\
\hline Subjects $\mathrm{n}$ & 17 & 60 \\
S-PIIINP $\mu \mathrm{g} \cdot \mathrm{L}^{-1}$ & $2.7 \pm 0.9$ & $3.6 \pm 1.0^{*}$ \\
BALF-PIIINP $\mu \mathrm{g} \cdot \mathrm{L}^{-1}$ & $0.1 \pm 0.5$ & $5.8 \pm 9.9^{* * *}$ \\
ELF-PIINP $\mu \mathrm{g} \cdot \mathrm{L}^{-1}$ & $9.7 \pm 33.8$ & $429 \pm 1073^{* * *}$ \\
S-PICP $\mu \mathrm{g} \cdot \mathrm{L}^{-1}$ & $107 \pm 38.8$ & $119 \pm 42.3$ \\
BALF-PICP $\mu \mathrm{g} \cdot \mathrm{L}^{-1}$ & $0.0 \pm 0.0$ & $4.8 \pm 9.1(\mathrm{n}=57)^{* *}$ \\
ELF-PICP $\mu \mathrm{g} \cdot \mathrm{L}^{-1}$ & $0.0 \pm 0.0$ & $246 \pm 447^{* *}$ \\
\hline
\end{tabular}

Values are mean \pm SD. S-PIIINP: serum aminoterminal propeptide of type III procollagen; BALF: bronchoalveolar lavage; ELF: epithelial lining fluid; S-PICP: serum carboxyterminal propeptide of type I procollagen. The significance of the changes was tested with Mann-Whitney U-test. *: $\mathrm{p}<0.05$; **: $\mathrm{p}<0.01 ; * * *: \mathrm{p}<0.001$.

BALF-PICP was detectable in 22 out of 57 sarcoidosis patients, while in the controls BALF-PICP could not be detected (table 2). Similarly, concentrations of PIIINP and PICP in ELF were significantly higher in the sarcoidosis group than in the controls. ELF concentrations of PIIINP were always, and PICP in 19 out of 22 cases, higher than the corresponding serum value (data not shown). In the sarcoidosis group the average concentration of PIIINP in ELF was 121 times and PICP twice higher than in the serum (table 2).

In sarcoidosis no correlation was found between S-PIIINP and BALF-PIIINP ( $\mathrm{r}=0.24$ ) or S-PICP and BALFPICP $(\mathrm{r}=0.16)$ while BALF-PICP and BALF-PIIINP correlated significantly (fig. 1). Neither BALF-PIIINP nor BALF-PICP correlated with FVC ( $\mathrm{r}=-0.07$ and -0.22 , respectively) or the $T \mathrm{~L}, \mathrm{CO} / V^{\prime} \mathrm{A}(\mathrm{r}=-0.11$ and -0.19$)$. BALFPIIINP correlated with S-ACE, S-IL-2R, BALF-albumin and BALF-lymphocytes (fig. 1), while BALF-PICP correlated only with BALF-lymphocytes $(\mathrm{r}=0.37)$ and BALFalbumin $(r=0.34)$ and not with S-ACE $(r=0.16)$ or S-IL-2R $(r=0.17)$. In the control group, the serum and BALF values of the procollagen markers did not correlate with each other, nor was there any correlation between these markers and BALF-albumin or lymphocytes.

In the patients with parenchymal involvement, S-ACE and BALF-PIIINP were significantly higher in patients with parenchymal sarcoidosis than in the patients with nonparenchymal disease, while S-IL-2R, S-PIIINP, S- and BALF-PICP, BALF-albumin and BALF-lymphocytes did not differ between these groups. The results were similar when the procollagen parameters were expressed as concentrations either in BALF or in ELF (table 3).

Out of 60 patients, 45 had prominent symptoms typical for sarcoidosis. BALF-PIIINP, S-PIIINP (Ns, data not shown) BALF-PICP ( $\mathrm{p}<0.05$, table 4 ), S-ACE (ns, data not shown) and S-IL-2R ( $\mathrm{p}=0.001$, data not shown) show-ed a tendency to increase in symptomatic disease. When the symptomatic patients were further subdivided into parenchymal and nonparenchymal disease, a tendency for highest BALF-PIIINP and PICP values was observed in the groups of symptomatic patients especially in the parenchymal disease (table 4). Furthermore S-PIIINP was significantly higher in symptomatic than nonsymptomatic nonparenchymal sarcoidosis (symptomatic 3.77 $\pm 0.96 \mu \mathrm{g}$. $\mathrm{L}^{-1}$, nonsymptomatic $\left.2.89 \pm 0.77 \mu \mathrm{g} \cdot \mathrm{L}^{-1}, \mathrm{p}<0.01\right)$. Table 5 shows that lung function data did not differ significantly 

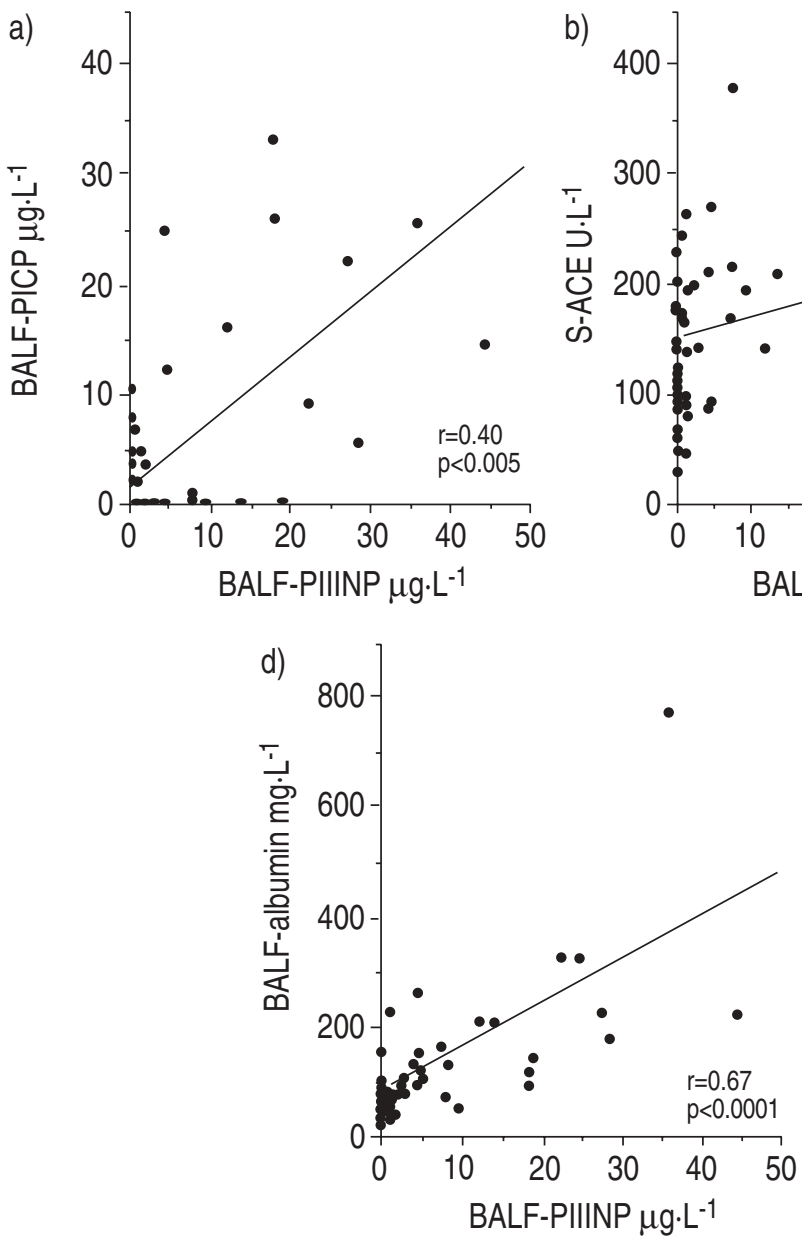
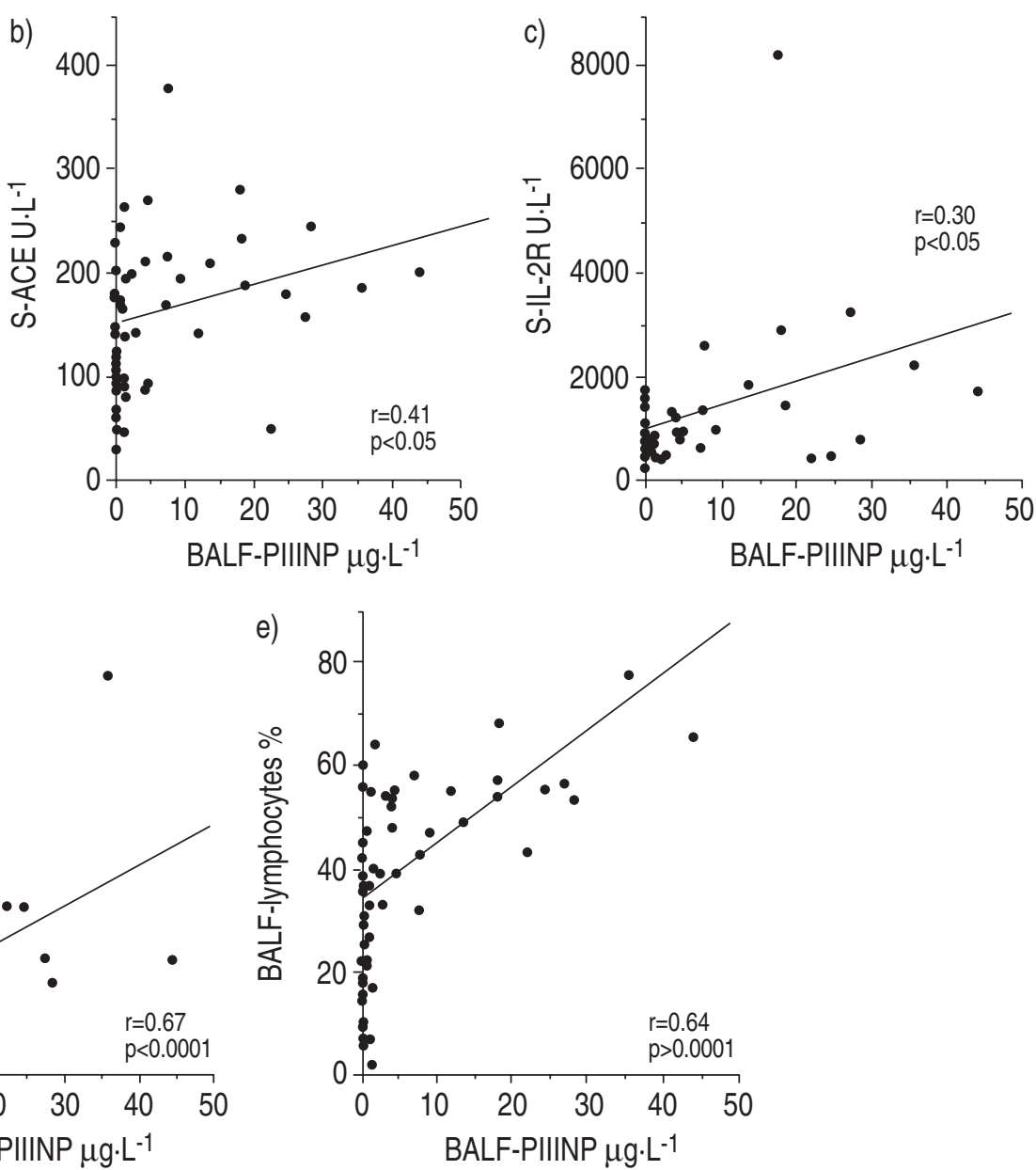

Fig. 1. - Relations of BALF-PIIINP to: a) BALF-PICP, b) S-ACE, c) S-IL-2R, d) BALF-albumin and e) BALF- lymphocytes in the sarcoidosis patients. Spearman correlation coefficients ( $r$ ) with p-values and the linear regression line as indicated in the subsets of the figure. S-ACE: serum level of angiotensin converting enzyme; S-IL-2R: serum interleukin-2 receptor. For further definitions, see legend to table 2.

Table 3. - Levels of S-ACE, S-IL-2R, S-PIIINP, S-PICP, BALF-albumin, BALF-lymphocytes, BALF- and ELF-PIIINP and BALF- and ELF-PICP in nonparenchymal and parenchymal sarcoidosis

\begin{tabular}{lcc}
\hline & $\begin{array}{c}\text { Nonparenchymal } \\
\text { sarcoidosis }\end{array}$ & $\begin{array}{c}\text { Parenchymal } \\
\text { sarcoidosis }\end{array}$ \\
\hline Subjects $\mathrm{n}$ & 40 & 20 \\
S-ACE $\mathrm{U} \cdot \mathrm{L}^{-1}$ & $139 \pm 59.1(\mathrm{n}=38)$ & $190 \pm 91.6^{*}(\mathrm{n}=18)$ \\
S-IL-2R mU.L & $948 \pm 613(\mathrm{n}=34)$ & $1537 \pm 1931 \quad(\mathrm{n}=16)$ \\
S-PIIINP $\mu \mathrm{g} \cdot \mathrm{L}^{-1}$ & $3.5 \pm 1.0$ & $3.6 \pm 1.1$ \\
S-PICP $\mu \mathrm{g} \cdot \mathrm{L}^{-1}$ & $116 \pm 37.3$ & $127 \pm 51.1$ \\
BALF-albumin mg $\cdot \mathrm{L}^{-1}$ & $111 \pm 124$ & $120 \pm 81.3$ \\
BALF-lymphocytes $\%$ & $35.8 \pm 18.5$ & $42.1 \pm 16.7$ \\
BALF-PIIINP $\mu \mathrm{g} \cdot \mathrm{L}^{-1}$ & $4.4 \pm 9.3$ & $8.7 \pm 10^{* *}$ \\
ELF-PIIINP $\mu \mathrm{g} \cdot \mathrm{L}^{-1}$ & $251 \pm 533$ & $785 \pm 1671^{* *}$ \\
BALF-PICP $\mu \mathrm{g} \cdot \mathrm{L}^{-1}$ & $3.7 \pm 8.2(\mathrm{n}=37)$ & $7.0 \pm 10.5$ \\
ELF-PICP $\mu \mathrm{g} \cdot \mathrm{L}^{-1}$ & $22 \pm 433$ & $290 \pm 482$ \\
\hline
\end{tabular}

Values are mean \pm SD. The significance of the changes was tested with Mann-Whitney U-test. *: $\mathrm{p}<0.05 ; * *: \mathrm{p}<0.01$. For definitions, see legends to table 2 and figure 1.

in nonparenchymal and parenchymal disease. Furthermore, when the lung function parameters were compared between the symptomatic and nonsymptomatic patients, the difference in parenchymal and nonparenchymal disease was not significant (table 5).
Table 4. - BALF-PIIINP and PICP finding in (S) symptomatic and nonsymptomatic $(\mathrm{N})$ sarcoidosis

\begin{tabular}{|c|c|c|}
\hline & $\begin{array}{c}\text { BALF-PIIINP } \\
\mu \mathrm{g} \cdot \mathrm{L}^{-1}\end{array}$ & $\begin{array}{c}\text { BALF-PICP } \\
\mu \mathrm{g} \cdot \mathrm{L}^{-1}\end{array}$ \\
\hline \multicolumn{3}{|c|}{ All patients } \\
\hline $\mathrm{S}$ & $7.4 \pm 10.9$ & $6.3 \pm 10.2 *$ \\
\hline $\mathrm{N}$ & $1.0 \pm 1.2$ & $0.8 \pm 1.9$ \\
\hline \multicolumn{3}{|c|}{ Nonparenchymal $(0-\mathrm{I})$} \\
\hline $\mathrm{S}$ & $5.8 \pm 10.6 \quad(n=29)$ & $4.9 \pm 9.5 \quad(n=26)$ \\
\hline $\mathrm{N}$ & $0.64 \pm 0.75 \quad(n=11)$ & $0.81 \pm 2.1 \quad(n=11)$ \\
\hline \multicolumn{3}{|c|}{ Parenchymal disease (II-III) } \\
\hline $\mathrm{S}$ & $11.0 \pm 11.5 *(n=15)$ & $9.1 \pm 11.5(n=15)$ \\
\hline $\mathrm{N}$ & $1.8 \pm 1.7 \quad(n=5)$ & $0.7 \pm 1.6 \quad(\mathrm{n}=5)$ \\
\hline
\end{tabular}

The values are mean \pm SD. The significance of the changes was tested with Mann-Whitney U-test. *: p<0.05 vs nonsymptomatic. S: symptomatic; N: nonsymptomatic. For further definitions, see legend to table 2 .

Since the number of mast cells in the BALF have been described to correlate with PIIINP values [13, 19], this was also assessed by correlating the percentage of BALF mast cells with these collagen parameters. There were significantly higher levels of PIIINP and PICP in those BALF samples which contained highest percentage of mast cells (table 6). 
Table 5. - Lung function parameters in nonparenchymal and parenchymal disease

\begin{tabular}{lrrrrr}
\hline & \multicolumn{2}{c}{$T \mathrm{~L}, \mathrm{CO} / V^{\prime} \mathrm{A}$} & & \multicolumn{2}{c}{$\mathrm{FVC}$} \\
\cline { 2 - 3 } \cline { 6 - 6 } \cline { 5 - 6 } & $\begin{array}{c}\mathrm{mmol} \cdot \mathrm{min}^{-1} \\
\mathrm{kPa}^{-1} \cdot \mathrm{L}^{-1}\end{array}$ & $\%$ pred & & $\mathrm{L}$ & $\%$ pred \\
\hline Nonparenchymal & $1.7 \pm 0.3$ & $105 \pm 18$ & & $4.8 \pm 1.1$ & $91 \pm 13$ \\
Parenchymal & $1.62 \pm 0.2$ & $104 \pm 16$ & & $4.1 \pm 1.1$ & $104 \pm 16$ \\
Nonparenchymal (0-I) & & & & \\
$\quad \mathrm{S}$ & $1.7 \pm 0.3$ & $105 \pm 20$ & & $4.9 \pm 1.1$ & $97 \pm 14$ \\
$\mathrm{~N}$ & $1.7 \pm 0.2$ & $106 \pm 10$ & $5.1 \pm 1.5$ & $99 \pm 17$ \\
Parenchymal (II-III) & & & & \\
$\mathrm{S}$ & $1.7 \pm 0.2$ & $107 \pm 17$ & $4.0 \pm 1.2$ & $89 \pm 13$ \\
$\mathrm{~N}$ & $1.5 \pm 0.2$ & $97 \pm 12$ & $4.6 \pm 0.9$ & $96 \pm 9$ \\
\hline
\end{tabular}

Values are mean \pm SD. The groups did not differ significantly (Mann-Whitney U-test). For definitions, see tables 1 and 4.

Table 6. - Levels of BALF-PIIINP and BALF-PICP with respect to the percentage of mast cells in sarcoidosis

\begin{tabular}{ccc}
\hline $\begin{array}{c}\text { Percentage of the } \\
\text { mast cells }(\mathrm{n}=45)\end{array}$ & $\begin{array}{c}\text { BALF-PIINP } \\
\mu \mathrm{g} \cdot \mathrm{L}^{-1}\end{array}$ & $\begin{array}{c}\text { BALF-PICP } \\
\mu \mathrm{g} \cdot \mathrm{L}^{-1}\end{array}$ \\
\hline 0 & $3.0 \pm 5.9$ & $3.6 \pm 8.0$ \\
1 & $11.1 \pm 14.0$ & $7.9 \pm 9.0$ \\
2 & $18.9 \pm 16.1^{* *}$ & $12.7 \pm 13.7^{*}$ \\
\hline
\end{tabular}

Values are mean \pm SD. The percentage of mast cells was obtained by counting the cells in May-Grünwald-Giemsa-stained cytocentrifuge preparations by light microscopy. The significance was tested with Mann-Whitney U-test. *: $<<0.05$ vs mast cell percentage of 0 and $1 ; * *: p<0.05$ vs mast cell percentage of 0 . For definitions, see legend to table 2.

\section{Discussion}

Our study showed that BALF-PIIINP and BALF-PICP were significantly elevated in sarcoidosis patients compared to controls, whereas S-PIIINP was elevated only marginally. Serum- and BALF-PIIINP values did not correlate with each other. Furthermore, BALF-PIIINP and S-ACE were higher in patients with parenchymal disease than in patients without parenchymal involvement, while S-IL-R2, S-PIIINP, S- and BALF-PICP did not differ significantly between these two groups. BALFPIIINP correlated significantly with S-ACE. Our finding that symptomatic patients with parenchymal involvement had higher BALF-PIIINP levels than nonsymptomatic patients may indicate an active pulmonary process in sarcoidosis. On the other hand, since S-PIIINP levels were higher in the symptomatic than in the nonsymptomatic nonparenchymal disease group, S-PIIINP may reflect general activity of this disease.

There have been contradictory reports concerning the significance of PIIINP in sarcoidosis. Low et al. [11] found increased concentrations of PIIINP in the BALF of sarcoidosis patients but no correlation of the peptide levels with clinical severity. Serum- or BALF-PIIINP has been reported to be elevated also in various other studies $[8,9$, 12, 14, 15, 29]. O'ConNor et al. [14] concluded that BALF-PIIINP is a poor indicator of the course and prognosis of this disease, and that an increase in BALF-PIIINP levels may reflect increased type III collagen synthesis associated with inflammatory process, rather than development of chronic lung disease. MLuan et al. [10] found no differences between BALF-PIIINP levels in sarcoidosis and controls. One reason for these discrepancies could be the use of different methods to assay the propeptide. In most earlier studies, bovine $\mathrm{N}$-terminal propeptide has been used as an antigen and without modifications for BALF samples the sensitivity of this assay designed for serum is low [29]. Also, pre-assay concentration of the samples can affect the results by chancing the relations of BALF proteins. Here we employed human antigen and have optimized the PIIINP assay for BALF measurements. The assay was sensitive enough to detect BALFPIIINP in two out of 17 control subjects and in 22 out of 60 sarcoidosis patients.

We also optimized PICP assay to detect low propeptide concentrations in BALF. S-PICP did not differ between the controls and patients, but BALF-PICP was significantly elevated and was positive in 22 out of 57 patients. It could not be detected in any one of the controls. S-PICP and BALF-PICP did not correlate with each other, which is consistent with the earlier finding that a vast majority of S-PICP is derived from the bone [27]. Thus, it seems obvious, that S-PICP is a poor disease indicator in pulmonary sarcoidosis.

BALF-PICP could theoretically be a useful marker for the development of progressive pulmonary fibrosis in sarcoidosis. In our study, BALF-PICP did not correlate with the disease activity assessed either by chest radiography or S-ACE measurement. However, in this type of crosssectional study it is not possible to assess the validity of this procollagen marker as a predictor for progressive lung fibrosis; this should be evaluated in a study of a prospective setting.

The standardization of BAL procedure is difficult, and therefore there is also fluctuation of the actual concentrations of the recovered molecules. As an attempt to circumvent the problem, ELF was quantified by using urea as a reference molecule. Higher concentrations of PIIINP and PICP in the ELF than in the serum suggests the active local synthesis of type I and III collagens in the lower respiratory tract.

Potential activity markers of sarcoidosis are clinical signs such as symptoms typical for sarcoidosis combined with the chest radiograph and lung function testing. Most of our patients had symptoms, but lung function parameters did not differ significantly between those patients with and those without symptoms. Lung function parameters did not differ significantly in the nonparenchymal and parenchymal disease either, a reason which can be attributed to the mild disease of our patients. Previous studies have shown that in sarcoidosis, lung function parameters are poor indicators of the disease activity and have very loose correlation with the chest radiograph findings [4]. In agreement, in our study the collagen parameters did not correlate with the lung function data.

We also observed a relationship between the percentage of BALF mast cells, and PIIINP or PICP, which is in agreement with previous results $[13,19]$. These results in this relatively small series of sarcoidosis patients may suggest that BALF mast cells in combination with the markers of collagen metabolism may help in assessing the activity of this disease. 
In conclusion, this study shows for the first time elevated carboxyterminal propeptide of type I procollagen (PICP) values in bronchoalveolar lavage fluid (BALF) of sarcoidosis patients. In contrast to the levels of aminoterminal propeptide of type III procollagen (PIIINP) in BALF which correlated with serum level of angiotensin converting enzyme and serum interleukin-2 receptor values, BALF-PICP did not. Our results further indicated that BALF-PIIINP and serum PIIINP (S-PIIINP) may reflect different, probably general aspects in sarcoidosis, BALFPIIINP being elevated in those patients with an active pulmonary involvement whereas S-PIIINP being elevated in symptomatic patients without pulmonary manifestation. As to PICP, further studies are needed to estimate its usefulness.

Acknowledgement: The authors wish to thank R. Jokela and J. Träskelin for their expert technical assistance.

\section{References}

1. Selroos $\mathrm{O}$. The frequency, clinical picture and prognosis of pulmonary sarcoidosis in Finland. Ph.D. Thesis, Faculty of Medicine University of Helsinki, Helsinki 1969.

2. Crystal RG, Bitterman PB, Rennard SI, Keogh BA. Interstitial lung disease of unknown cause. Disorders characterised by chronic inflammation of lower respiratory tract. N Engl J Med 1984; 310: 235-244.

3. Sharma OP. Markers of sarcoidosis activity. Chest 1986; 90: 471-473.

4. Costabel U, du Bois R, Eklund A, et al. Consensus conference: activity of sarcoidosis. Eur Respir J 1994; 7: 624627.

5. Lawrence EC, Brouseau KP, Berger MB, Kurman CC, Marcon L, Nelson DL. Elevated concentrations of soluble interleukin-2 receptors in serum samples and bronchoalveolar ravage fluids in active sarcoidosis. Am Rev Respir Dis 1988; 137: 759-764.

6. Tsutsumi T, Nagai S, Imai K, Setoyama Y, Uchiyama T, Izumi T. Soluble interleukin-2 receptor in blood from patients with sarcoidosis and idiopathic pulmonary fibrosis. Sarcoidosis 1994; 11: 102-109.

7. Poole A, Myllylä R, Davies BH. Activities of enzymes of collagen biosynthesis and levels of type III procollagen peptide in serum of patients with sarcoidosis. Life Sci 1989; 45: 319-326.

8. Luisetti M, Bulgheroni A, Baccella L, Pasturenzi L, Aprile C. Elevated serum procollagen III aminopeptide levels in sarcoidosis. Chest 1990; 98: 1414-1420.

9. Pohl WR, Thompson AB, Köhn H, et al. Serum procollagen III peptide levels in subjects with sarcoidosis. A 5-year follow-up study. Am Rev Respir Dis 1992; 145: 412-417.

10. Milman N, Kristensen MS, Bentsen K, Grode G, Fredriksen J. Hyaluronan and procollagen type III aminoterminal peptide in serum and bronchoalveolar ravage fluid in patients with pulmonary sarcoidosis. Sarcoidosis 1995; 12: $38-41$.

11. Low RB, Cutroneo KR, Davis GS, Giancola MS. Lavage type III procollagen $\mathrm{N}$-terminal peptides in human pulmonary fibrosis and sarcoidosis. Lab Invest 1983; 48: 755-759.

12. Bjermer L, Thunell M, Hällgren R. Procollagen III pep- tide in bronchoalveolar lavage fluid. A potential marker of altered collagen synthesis reflecting pulmonary disease in sarcoidosis. Lab Invest 1986; 55: 654-656.

13. Bjermer L, Engström-Laurent A, Thunell M, Hällgren R. The mast cell and signs of pulmonary fibroblast activation in sarcoidosis. Int Arch Allergy Appl Immunol 1987; 82: 298-301.

14. O'Connor C, Ward K, van Breda A, McIlgorm A, FitzGerald M. Type 3 procollagen peptide in bronchoalveolar lavage fluid: poor indicator of course and prognosis in sarcoidosis. Chest 1989; 96: 339-344.

15. Schaberg T, Orzechowski K, Oesterling C, Lode H, Schuppan D. Simultaneous measurements of collagen type-IV-related antigen and procollagen-III-N-propeptide levels in bronchoalveolar lavage. Eur Respir J 1994; 7 : 1221-1226.

16. Bachella L, Tinell C, Gigè LS, et al. Serum type I and type III procollagen peptide levels in sarcoidosis. Eur Respir J 1996; 9: 1648-1651.

17. Harf R, Biot N, Perrin-Fayolle M, et al. Prognostic value of ACE, lysozyme and pulmonary lymphocytosis in sarcoidosis. In: Grassi G, Rizzato G, Pozzi E, eds. Sarcoidosis and Other Granulomatous Disorders. Amsterdam, Elsevier, 1988; pp. 595-597.

18. Costabel U, Bross KJ, Nilles A, et al. Predictive value of bronchoalveolar T cell subsets for the course of pulmonary sarcoidosis. Ann N Y Acad Sci 1986; 465: 418-426.

19. Bjermer L, Rosenhall L, Hällgren R. The predictive value of bronchoalveolar lavage cell analysis in sarcoidosis. Thorax 1988; 43: 284-288.

20. Bateman E, Turner-Warwick M, Adelman-Grill BC. Immunohistochemical study of collagen types in human foetal lung fibrotic lung disease. Thorax 1981; 36: 645-653.

21. Risteli J, Risteli L. Analysing connective tissue metabolites in human serum. Biochemical, physiological and methodological aspects. J Hepat 1995; 22 (Suppl. 2): 7781.

22. Anttinen H, Terho EO, Järvensivu PM, Savolainen E-R. Elevated serum galactosylhydroxylysyl glucosyltransferase, a collagen synthesis marker, in fibrosing lung diseases. Clin Chim Acta 1985; 3: 3-8.

23. Anttinen H, Terho EO, Myllylä R, Savolainen ER. Two serum markers of collagen biosynthesis as possible indicators of irreversible pulmonary impairment in farmers lung. Am Rev Respir Dis 1986; 133: 88-93.

24. Fraser RS, Paré JAP, Fraser RG, Paré PD. Synopsis of diseases of the chest. W.B. Saunders, 1994; pp. 202-208.

25. Harjanne A. Automated kinetic determination of angiotensin converting enzyme in serum. Clin Chem 1984; 30: 901-902.

26. Risteli J, Niemi S, Trivedi P, Mowat AP, Risteli L. Rapid equilibrium radioimmunoassay for the amino-terminal propeptide human type III procollagen. Clin Chem 1988; 34: 715-718.

27. Melkko J, Niemi S, Risteli L, Risteli J. Radioimmunoassay of the carboxyterminal propeptide of human type I procollagen. Clin Chem 1990; 36: 1328-1332.

28. Rennard S, Basset G, Lecossier D, et al. Estimation of absolute volume of epithelial lining fluid recovered by bronchoalveolar lavage by using urea as an endogenous marker of dilution. J Appl Physiol 1986; 60: 532-538.

29. Risteli L, Risteli J. Non-invasive methods for detection of organ fibrosis. In: Rojkind M, ed. Connective Tissue in Health and Disease. Boca Raton, CRP Press 1990; pp. $61-98$. 